. Research Article

\title{
The Role of Audio and Visual Media in Improving English-Speaking Proficiency from Saudi College Students' Perspective
}

\author{
Mamoon M. Alaraj \\ Language Support Unit Faculty Of Engineering King Abdulaziz University Kingdom Of \\ Saudi Arabia
}

\begin{abstract}
:
This study aims to deeply explorethe Saudi college students' perspective about the role of audio and visual English mediain developing theirEnglish-speaking proficiency. To arrive to the best results possible, a focus group of five college students who were interested in improving their English proficiency was formed. Following the brainstorming technique, they created a questionnaire of six multiple choice, checkbox, rating, and scale questions which was reviewed by three experts and piloted on 30 students, improved accordingly, created by Google Forms, and finally distributed via WhatsApp groups. College students who were interested in improving their English-speaking proficiency and used to listen to and/or watch English media were requested to respond to the questionnaire. A sample of 65 college students' responses were received and the data was analyzed by Google Forms. The major results revealed that: -the immense majority of students believed that the English media could affect their speaking proficiency, -YouTube, social media, songs, and movies were the most repetitively and continuously used by students, -YouTube and movies were the types of media that affected the speaking proficiency the most and -pronunciation was the most affected area by the media. Related educational recommendations and deeper further studies were suggested.
\end{abstract}

Key words: Audio, Visual, Media, English, Speaking, Proficiency, College, Students

\section{Introduction}

Speaking, as a productive or active skill, is the twin of the other productive skill, writing (British Council, 2020). However, compared to writing, speaking is considered the natural tool for communication and it is used much more than writing (Hossain, 2015). We all speak to communicate our thoughts and ideas, but most of the time we face problems and difficulties (Al Hosni, 2014). Saudi college students like all other students face obstacles and challenges when learning and using English as a foreign languagein general and most students find it very difficult and challenging to learn and practice the speaking skill in particular (Souriyavongsa et al., 2013; Alaraj, 2017). According to (Leong \&
Ahmadi, 2017)speaking is by far the most difficult skill to master. Students find it easier to deal with listening and reading as receptive skills, but there are many hinders in the way of building speaking and writing proficiency. For some reasons, that could be investigated in a separate paper, most students find it easier to write than to speak. Since speaking is the main tool of communication for college students, improving and building speaking proficiency is actually a big challenge that needs more and more attention and consideration by learners, teachers and researchers (Al-Nasser, 2015; Shadiev\& Yang, 2020). There are many techniques and strategies for learning the English-speaking skill. In this research article, the strategy of using the audio and visual media for improving and building a solid 
speaking proficiency is investigated. This technique or strategy is chosen because it is widespread and accessible probably for all students nowadays. Although listening to conversations and watching videos could have an immense effect on speaking proficiency (English with Kim website, 2020; Shehada\& Amer, 2018), very few students consciously spend enough time on this available chance and little interest and attention is paid to this way of learning by teachers and researchers. And it seems that those students who watch TV shows and movies and listen to English conversations in their free time do notconsciouslytry to benefit fromthis valuable learning strategy.This research paper comes in this context; it tries to identify the audio and visual media used to enhance and improve the speaking proficiency and investigate how this strategy could affect improving the Saudi college students' speaking proficiency.

The research questions (RQs) of this study are as follows:

RQ1: What are the audio and visual English media that are used by Saudi college students the most?

RQ2: How could the audio and visual English media affect Saudi college students' Englishspeaking proficiency?

\section{Methodology}

To arrive to the best results possible for the above two RQs, a well-developed survey was used as a data collection tool. A focus group of fivecollege students who were interested in improving their English proficiency was formed and guided by their English teacher, the researcher himself. They first discussed the problem of the study and the two RQs.They were then requestedto follow the brainstorming technique to create a questionnaire that can help in answering these twoRQs. The aim was to reach deep, comprehensive, and reliable answers. To go deep into the answers of the research RQs, six multiple choice, checkbox, rating, and scale questions were formulated. The draft invented was given to three experts to review, proofread and edit. The final draft of the survey was piloted on 30 students, improved accordingly(See appendix A),created by Google Forms, and finally distributed via WhatsApp groups.College students who were interested in improving their English-speaking proficiency and used to listen to and/or watch English media were requested to respond to the questionnaire. A sample of 65 college students'responses were received and the data was analyzed by Google Forms.

\section{Results}

In this part of the study,the results of the questionnaire were displayed in nine figures:six graphs and three tables. The first threefigures tried to answer the first RQ and the other sixtried to answer the second RQ.

The first RQ was as follows: What are the audio and visual English media that are used by Saudi college students the most?

The following two graphs and the table below tried to answer this question.

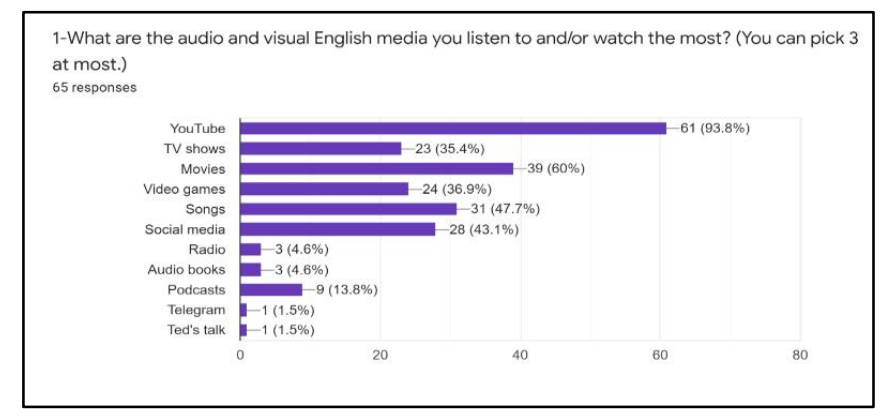

Figure 1:The frequency of using audio and visual English media by Saudi college students

As can be obviously seen from figure 1 , as expected the vast majority voted for the YouTube, 61 out of 65 college students used to watch this media in English. In the second place with about two thirds of the participants came Movies, 39 out of 65 students used to watch this media. Songs and Social media occupied the third position with just under a half for the Songs and $43 \%$ for the Social media, 31 and 28 out of 65 participants, respectively. In the fourth place, just under a third played Video games and watched TV 
shows. In comparison, very few students used tolisten to the rest of the media types.

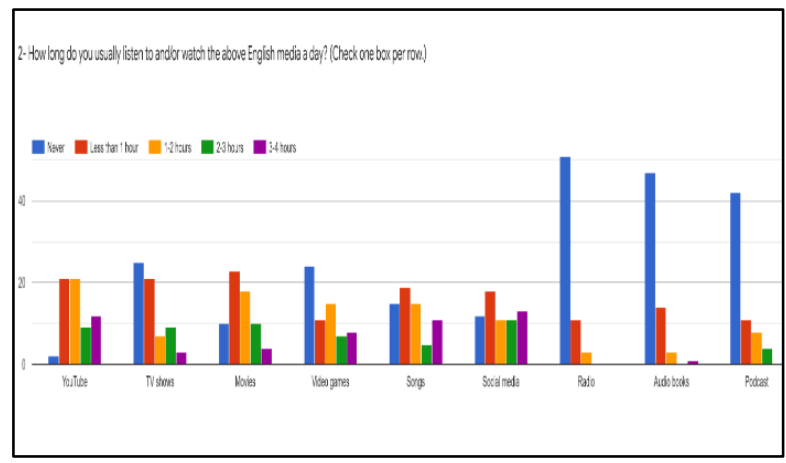

Figure 2: The duration of using audio and visual media by Saudi college students a day

From figure 2 above, it can be calculated that Social media,YouTubeand Songsoccupied the highest number of hours. Respectively,13, 12 and 11 out of 65 college students used these three types of media in English for 3-4 hours. Came next Video games with 7 out 65 students who played these games for 3-4 hours. In comparison, not more than 5 to 4 students watched Movies and TV shows. Surprisingly, only one student listened to Audio books and no students chose Radio or Podcast. Excluding to someextentSongs and includingMoviesand TV shows, the media which captured the highest number of hours again occupied the 2-3 hours interval, with 10 students for Social media and Movies, 8 for both YouTube and TV shows and 6 for Video games.From 1-2 hours YouTube was again in the first place with 21 students, followed byMovies with 17 students, Video games and Songs with 15 students for both, and Social media with 10 voters. Finally, came Podcast with 7, TV shows with 6 and Radio and Audio books with 3 for both.

To be more accurate, the exact number of hours students listened to and/or watched each type of media a day was calculated in this table.

\begin{tabular}{|c|c|c|c|c|c|c|c|}
\hline Duration & & $\begin{array}{c}\text { Less than } \\
\text { an hour } \\
(1 / 2 \text { an } \\
\text { hour on } \\
\text { average })\end{array}$ & $\begin{array}{c}1-2 \\
\text { hours }(1 \\
\text { hour \& } \\
\text { a } 1 / 2 \text { on } \\
\text { average })\end{array}$ & $\begin{array}{c}2-3 \\
\text { hours }(2 \\
\text { hours \& } \\
\text { a } 1 / 2 \text { on } \\
\text { average })\end{array}$ & $\begin{array}{c}3-4 \text { hours } \\
(3 \text { hours } \\
\& \text { a } \\
1 / 2 \text { on } \\
\text { average })\end{array}$ & $\begin{array}{c}\text { Total No. } \\
\text { of } \\
\text { responses }\end{array}$ & $\begin{array}{c}\text { Total } \\
\text { No. of } \\
\text { hours } \\
\text { a day }\end{array}$ \\
\hline YouTube & 2 & 21 & 21 & $\mathbf{8}$ & 13 & 65 & 107.5 \\
\hline TV shows & 25 & 22 & 6 & 9 & 3 & 65 & 53 \\
\hline Movies & 10 & 23 & 18 & 10 & 4 & 65 & 77.5 \\
\hline $\begin{array}{c}\text { Video } \\
\text { games }\end{array}$ & 25 & 11 & 15 & 6 & $\mathbf{8}$ & 65 & 71 \\
\hline Songs & 16 & 18 & 15 & 4 & 12 & 65 & 83.5 \\
\hline $\begin{array}{c}\text { Social } \\
\text { media }\end{array}$ & 12 & 17 & 11 & 11 & 14 & 65 & 101.5 \\
\hline Radio & 51 & 11 & 3 & 0 & 0 & 65 & 10 \\
\hline $\begin{array}{c}\text { Audio } \\
\text { books }\end{array}$ & 47 & 14 & 3 & 0 & 1 & 65 & 15 \\
\hline Podcast & 42 & 12 & 7 & 4 & 0 & 65 & 26.5 \\
\hline
\end{tabular}

Figure 3: The duration of using audio and visual media by Saudi college students a day

Concerning how long college students spent time listening to and/or watching audio and visual English media, figure 3 above revealed that YouTube and Social media dominated the peak with 107.5 and 101.5 hours a day, respectively. As can be seen obviously there was a sudden drop when it came to Songs, Movies and Video games which had a duration of $83.5,77.5$ and 71 hours, respectively. In the third place came TV shows with 53 hours a day followed by Podcast with 30.5 hours. One more drop can be read out concerning Audio books and Radio which had only 15 and 10 hours a day, respectively.

The second RQ was as follows:How could the audio and visual English media affect Saudi college students' English-speaking proficiency?

The following four graphs and two tablestried to answer this question.

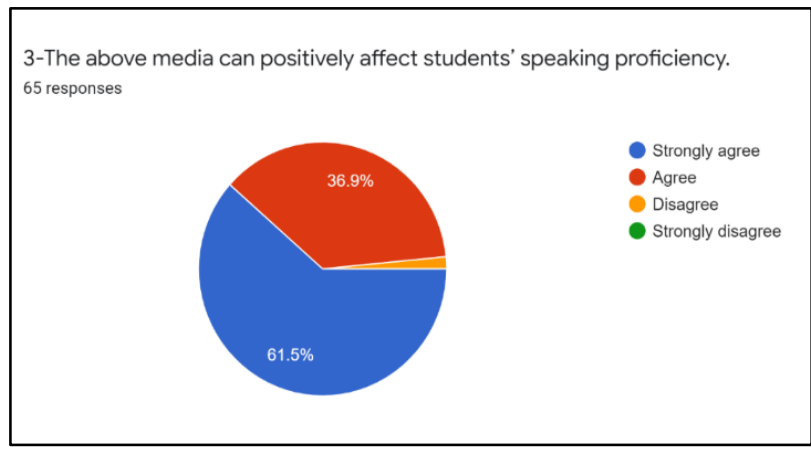

Figure 4: The extent to which the English media affect Saudi college students' speakingproficiency 
Figure 4 simply revealed college students' perspective concerning the extent to which they believed the English media could affect their speaking proficiency.The immense majority of the participants voted for agreement with a total of $98.9 \%$ (just under two thirds strongly agreed and just above one third agreed), and only $1.6 \%$ believed that the English media had no effect on students' speaking proficiency.

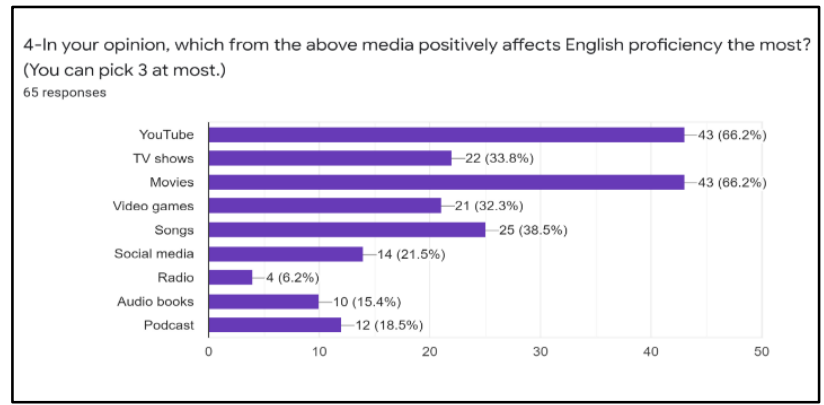

Figure 5: Effectiveness of English media in Saudi college students' speaking proficiency

To go deep into answering RQ2, the students' opinion on the types of media that affected the speaking proficiency the most was surveyed.The nine types of media could be divided into three levels of effectiveness: high, medium and low.YouTube and Moviesdramatically exceeded the other options with two thirds for each as shown in figure 5 above. Songs, Tv shows and Video gameswerein the second position with about a quarter. And finally came Social media, Podcast and Audio books. According to students' opinion Radio had a very limited effectiveness.

Having an insight into the results above, surprisingly, there were six areas of agreement on what was being listened to and/or watched and what students believed about the effectiveness of these types of media indeveloping speaking proficiency. However, it could be also noticed that there were three areas of difference/partial difference where students did not necessarily watch and/or listen to the type of media they believed had more effectiveness in improving theirspeaking proficiency. This table summarizes thesimilarities and differences between the
frequency(See figure 1.) and duration(See figures 2, and 3.) of listening to and/or watching these types of media on one side and students' opinions about the effectiveness(See figure 5.) of these types in improving speaking proficiency on the other side.

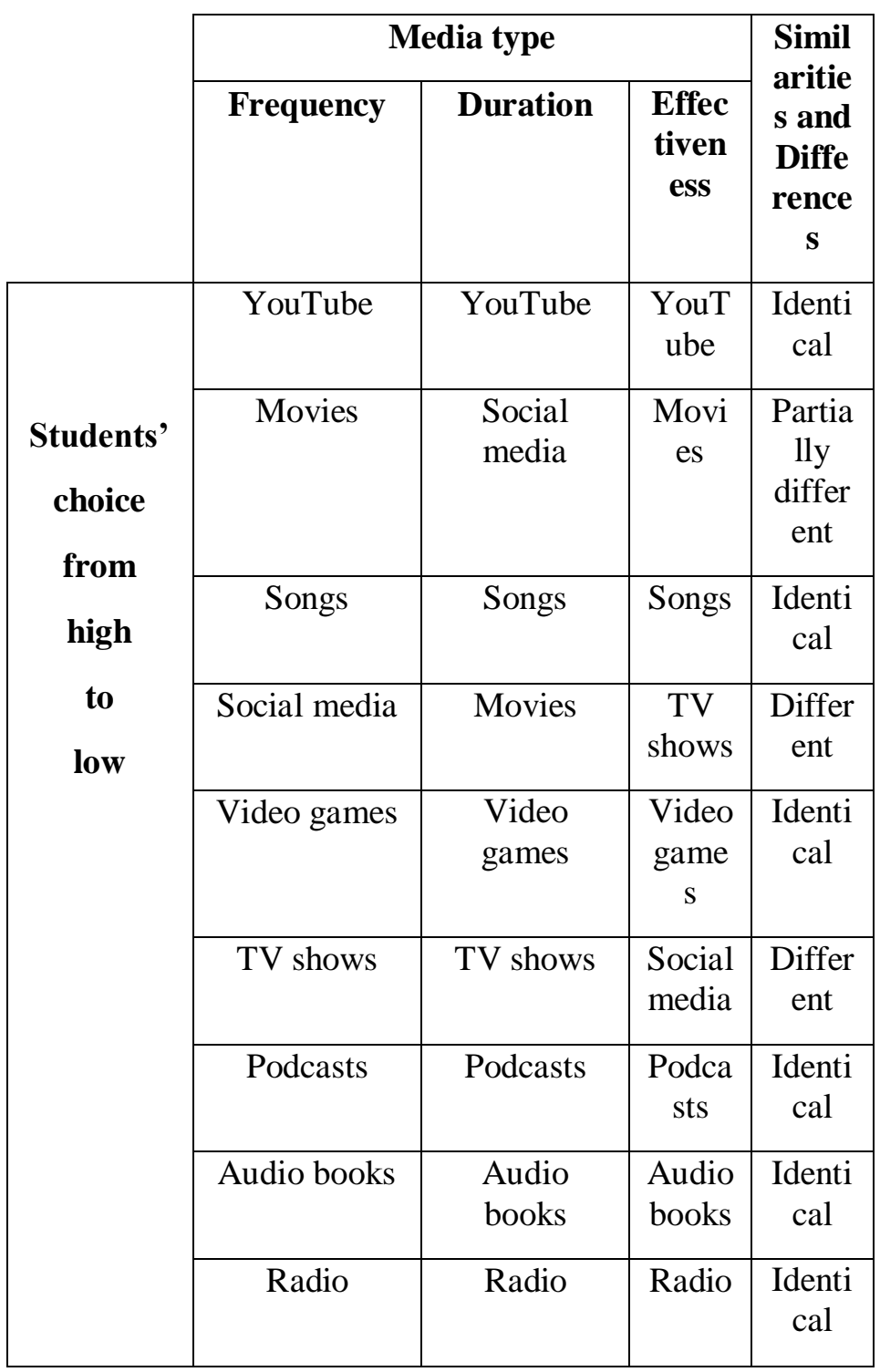

Figure 6: Similarities and differences between frequency, duration, and effectiveness of listening to and/or watching English media types

As can be obviously seen in figure 6 above, there were six identical areas (YouTube, Songs, Video games, Podcasts, Audio books, and Radio) where students frequently and continuously watched and/or listened to various types of media on the one hand and thought of an effectiveness of these media in 
improving speaking proficiency on the other hand. ConcerningMovies, students chose the same level of frequency and effectiveness, but the duration was two levels lower than the effectiveness. Regarding TV shows, students gave the same level of duration and frequency on the one hand, but a higher level of effectiveness on the other hand. Finally, Social mediashowed completely different levels of duration, frequency, and effectiveness. It was given two levels of duration higher than frequency on the one side and two levels of effectiveness lower than frequency and four levels lower than duration.

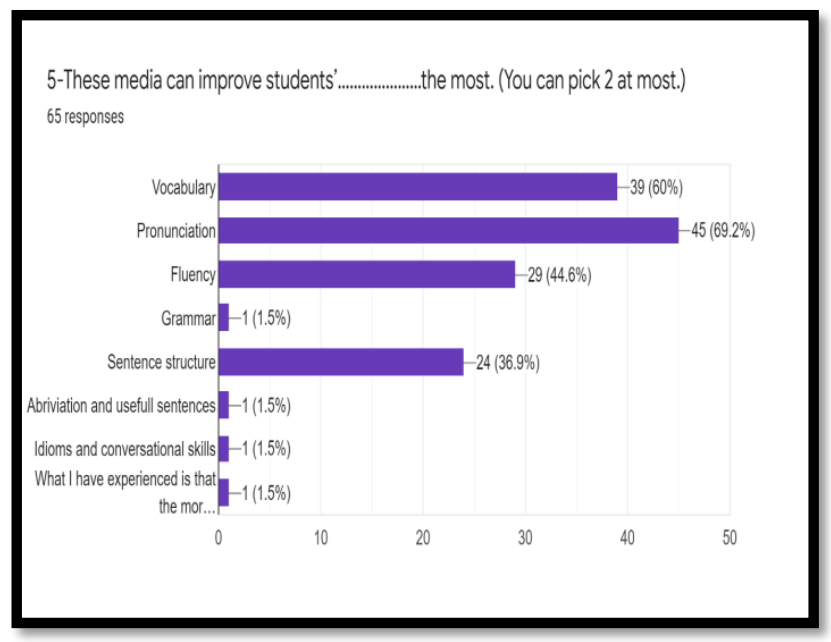

Figure 7: The various language areasthat canbe improved by the English media the most

Going deeper into investigating RQ2, the participants were asked to determine which language areas could be affected by the English media the most. Again, the eight areas (the first 5 specified by the researcher and the last 3 added by the respondents) could be divided into three categories: high, medium and low improvement. As revealed in figure 6above, Pronunciationand Vocabulary were the most affected with above two thirds and just under a third, respectively. Then Fluency and Sentence structure captured the second position with just under a half and just above a third, respectively. Grammar, Abbreviations, andIdioms were placed in the last category with a very little improvement, $1.5 \%$ each.

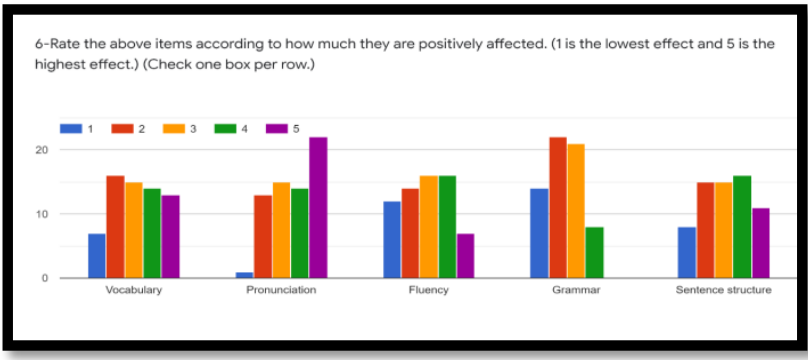

Figure 8: The extent to which the various areaswere affected by the English media

Going deeper and deeper, the participants were asked to rate the five main language areas according to the extent they were positively affected by the English media. This graph is similar in purpose to the previous one, figure 6. However, it attempted to go deeper and give more specific values to the influence and improvement that happened to these five language areas. Ascan be seen in figure 7 above, Pronunciation occupied the highest level (5) concerning the effectiveness of English media on speaking proficiency with 22 out of 65 participants, followed byVocabulary and Sentence structure with 13 and 11, respectively.Finally, Fluency came next with 7 participants and no students chose Grammar to be highly affected. Regarding the next highest level (4), four areas received a similar evaluation: 16, 16, 14 and 14 out of 65 for Fluency, Sentencestructure, Pronunciation and Vocabulary, respectively. Grammar again was placed in the end with only 8 votes. In comparison, the graph above showed the opposite order for Grammar to be on the top of level 3 and 2 ( 21 and 22 out of 65 votes), and the other four areas with a similar level between 13 to 16 out of 65 . Finally, Grammar and Fluency were elected to be in level 1 by 14 and 12 participants, respectively, followed by Sentence structure and Vocabulary with 8 and 7, and lastly Pronunciation with only 1 participant.

To be more accurate, the extent to which the various areas were affected by the English media was calculated in this table. 


\begin{tabular}{|c|c|c|c|c|c|c|c|}
\hline$\underbrace{\text { Effec }}$ & $\begin{array}{c}\text { High } \\
\text { est } \\
5\end{array}$ & $\overline{4}$ & $\overline{\mathbf{3}}$ & $\overline{2}$ & $\begin{array}{c}\text { Low } \\
\text { est } \\
1\end{array}$ & \multirow{2}{*}{$\begin{array}{c}\text { Tota } \\
\text { I No. } \\
\text { of } \\
\text { resp } \\
\text { onse } \\
\text { S }\end{array}$} & \multirow{2}{*}{$\begin{array}{c}\text { Total } \\
\text { degre } \\
\text { e of } \\
\text { effect } \\
\text { ivene } \\
\text { ss }\end{array}$} \\
\hline $\begin{array}{c}\text { Expr } \\
\text { essio } \\
n\end{array}$ & \multicolumn{5}{|c|}{ No. of Responses } & & \\
\hline $\begin{array}{c}\text { Voca } \\
\text { bular } \\
\mathbf{y}\end{array}$ & 13 & 14 & 15 & 16 & 7 & 65 & 205 \\
\hline $\begin{array}{l}\text { Pron } \\
\text { uncia } \\
\text { tion }\end{array}$ & 22 & 14 & 15 & 13 & 1 & 65 & 238 \\
\hline $\begin{array}{c}\text { Fluen } \\
\text { cy }\end{array}$ & 7 & 16 & 16 & 14 & 12 & 65 & 187 \\
\hline $\begin{array}{c}\text { Gra } \\
\text { mma } \\
\text { r }\end{array}$ & $\mathbf{0}$ & 8 & 21 & 22 & 14 & 65 & 153 \\
\hline $\begin{array}{l}\text { Sente } \\
\text { nce } \\
\text { Struc } \\
\text { ture }\end{array}$ & 11 & 16 & 15 & 15 & 8 & 65 & 202 \\
\hline
\end{tabular}

Figure 9: The extent to which the various

areas were affected by the English media

Concerning the extent to which the various areas were affected by the English media, figure 8 above revealed that Pronunciation dominated the peak with 238 degree of effectiveness. As can be seen obviously there was a sudden drop when it came to Sentence structure, Vocabulary and fluency which had degrees of 202, 205 and 187. Showing one more drop,Grammarcame in the lowest place with 153 degree.

\section{Discussion:}

This research tried to investigate the role of audio and visual media in improving English speaking proficiency from Saudi collegestudents' perspective. As previously mentioned, the research problem is the learning deficiency of the English-speaking skill among the Saudi college students. Like all other students, Saudi students face problems and difficulties and find it very difficult to learn and practice the speaking skill in particular.The major findingsrevealed by the answers of the twoRQs are as follows:

1- It was clear that studentsfrequently used visual English media much more than audio media (See figure 1). They also spent much more time watching visual English media than listening to audio media (See figures 2 and 3).

2- YouTube, social media, songs, and movieswere the most repetitively and continuously used by students, followed by video games and TV shows (See figures 1, 2, and 3).

3- Concerning the extent to which students believed the English media could affect their speaking proficiency, the immense majority voted for agreement (See figure 4).

4- Regarding students' opinion on the types of media that affected the speaking proficiency the most, the nine types of media could be divided into three levels of effectiveness, high: YouTube and movies, medium: songs, Tv shows and video games, and low: social media, podcasts and audio books. According to students' opinion, radio had a very limited effectiveness (See figure 5).

5- There were six areas of agreement on what was being listened to and/or watched compared to what students believed about the effectiveness of these types of media on speaking proficiency. However, it could be also noticed that there were three areas of difference/partial difference where students did not necessarily watch and/or listen to the type of media they believed had more effectiveness in improving their speaking proficiency (See figure 6).

6- Regarding the extent to which the various areas were improved and affected by the English media, pronunciation dominated the peak of effectiveness, followed by a sudden drop regarding sentence structure, vocabulary, and fluency. Showing one more drop grammar came in the lowest place (See figures 7, 8 and 9).

The world of today is the world of media and people of today receive the media with and from the air they breathe. This makes media a 
constant and excellent source to learn from. According to (Student Counselling Service, 2016), the more human senses are involved in a situation, the better an individual can fully live that situation and as a result experience, learn and memorize what he/she has been exposed to.In this context we can understand why such adult students prefer not only to listen to, but also to watch what is being shown on the various types of media.Taking into account that speaking is the main tool and the key means of human interaction and communication, the immense majority of students agree that media in general and visual types of media in particular positively affect their speaking ability, if not speaking, what could be affected?

Culture is like a glass from which people drink language. Every language has its own culture and the relationship between the two is an animate and authentic one. According to (Clear Words Translations, 2017), to comprehensively and deeply learn a language, it should be put in a cultural context, otherwise something would seem missing and the situation would lack its lively meaning. And what is a better way to expose yourself to the culture than media? In this context we can realize why such students prefer to watch visual types of media rather than to listen to other types that lack clear cultural aspects,animation, andauthenticity. This could be the reason that stands behind their preference and giving priority to YouTube and movies to be the most used and considered as a source of positive effectiveness on speaking proficiency. On the contrast, they show a relative lack of interest in social media, podcasts, and audio books. And in the middle, they place songs, TV shows and video games. Radio is considered to have a very limited effectiveness.

Now why results show a very high level of similarity and agreement between what is being listened to and/or watched compared to what students believe about the effectiveness of these types of media on speaking proficiency? For example, they watched YouTube more frequently and for longer time than the other types of media and believe that YouTube has the highest level of effectiveness on improving their speaking proficiency. It could be the mixture of authenticity and animation features the YouTube has with the potential desire in students to improve their English in general and their speaking ability in particular thatleads to such agreement and similarity. That desire maybe emerges from the idea that put those who can speak English fluently in an appearance of a prestigious and impressive situation among others. Concerning the other types of media, although there are some slight differences in their level places, all the visual typescome first and have higher levels of frequency and duration of watching visual types than levels of listening to audio types. Academic purposes and communicating with teachers could be one more reason which interprets this similarity. Those college students' need to improve their English language and their speaking proficiency in order to understand the scientific content they study and to easily communicate with their teachers, and this perhaps leads to similar duration and frequency of higher levels of watching visual types with their belief of the effectiveness of such types than listening to audio types.

Pronunciation is one if not the most difficult area of learning a foreign language. And this is the case here for Saudi students (Alaraj, 2016; Alaraj, 2017). That is probably why pronunciation dominates the peak of effectiveness according to those students. They possibly think that because their pronunciation is originally weak, and they feel the difference in improvement over the days. Concerning grammar, it could be the nature of this area of language that needs purposeful and previous preparation and direct teaching which is not available in media. This is probably why grammar comes in the lowest place where media affects language areas. Regarding sentence structure, vocabulary, and fluency, it maybe their nature, which is opposite to grammar, namely these expressions could be acquired spontaneously and unintentionally, that place them in the middle position. They 
are less difficult than pronunciation and do not necessarily need what grammar needs of purposeful preparation and direct teaching to be acquired.

\section{Conclusion:}

In conclusion, the world of media has an intensive and extensive material that could be invested in education in general and in teaching English as a foreign language in particular. Educators and teachers can make use of this cultural, authentic and animated material to help English learners improve their English language, especially their speaking abilities, by creating special learning-directed activities. If students have the purpose of improving their speaking proficiency in mind while watching the various types of media, the opportunity to advance all related speaking areas will be greater. According to this study,visual media have moreindirect, positive, and effective impact on the speaking proficiency than audio media. This is because the more human senses are involved in the learning process, the better a learner can absorb the targeted content. Although this study was conducted in a specific region, the results could be generalized in similar places where English is used as a foreign language. Further suggested studies could be carried out to investigate individualizing the idea of making use of the media in improving the different English language skills where a student can choose to listen to and/or watch what he/she thinks more effective to positively advance his/her targeted skill

\section{References}

a. Alaraj, M. (2017). EFL Speaking Acquisition: Identifying Problems, Suggesting Learning Strategies and Examining Their Effect on Students' Speaking Fluency. The International Journal of Social Sciences and Humanities Invention, 4(1): 3215-3221.

b. Alaraj, M. (2016). EFL Acquisition External Problems and Difficulties: An Investigative Interview to Examine Saudi Students'
Thoughts and Feelings. Journal of Language Teaching and Research, 7(3): 484-490.

c. Al Hosni, S. (2014). Speaking Difficulties Encountered by Young EFL Learners. Indiana University

Bloomington.https://www.researchgate.net/pu blication/270340628_Speaking_Difficulties_E ncountered_by_Young_EFL_Learners

d. Al-Nasser, A. (2015). Problems of English Language Acquisition in Saudi Arabia: An Exploratory-cum-remedial Study. Theory and Practice in Language Studies, 5(8): 16121619.

e. British Council, Teaching English, Productive Skills.https://www.teachingenglish.org.uk/artic le/productive-skills

f. Clear Words Translations. (2017).Is Understanding Culture Essential to Learning a Language?http://clearwordstranslations.com/la nguage/en/learning-a-language/

g. English with Kim Website. (2020). Use Your Listening Skills to Improve Your Speaking and Conversation Skills in English. https://englishwithkim.com/listening-skillsimprove-speaking/

h. Hossain, M. (2015). Teaching Productive Skills to the Students: A Secondary Level Scenario Department of English and Humanities. BRAC University, Dhaka, Bangladesh.

i. Leong, L. \& Ahmadi, S. (2017). An Analysis of Factors Influencing Learners' EnglishSpeaking Skill. International Journal of Research in English Education, 2(1).

j. Shadiev, R. \& Yang, M. (2020). Review of Studies on Technology-Enhanced Language Learning and Teaching. School of Education Science, Nanjing Normal University, Nanjing, China.

k. Shehada, S. \& Amer, O. (2018). Perceptions of Palestinian Students towards Using Audio Visual Aids in the English Language Classroom at the University Level. Journal of Palestinian Journal of Open Learning \& eLearning, 7(13).

1. Souriyavongsa, T. et al. (2013). Factors Causes Students Low English Language Learning: A Case Study in the National University of Laos. English in Education, 1(1): 179-192.

m. Student Counselling Service. (2016). Long- and Short-Term Memory. The University of Chicago. https://courses.lumenlearning.com/austincc- 
Mamoon M. Alaraj/The Role of Audio and Visual Media in Improving English-Speaking Proficiency from Saudi College Students' Perspective

learningframeworks/chapter/chapter-9-memoryand-information-processing

\section{Appindix A \\ Questionnaire}

Assalamu Alaikum! I am Mamoon Alaraj, a professor in the Faculty of Engineering at King Abdelaziz University, Jeddah. I am conducting a survey about the Role of Audio and Visual Media in Improving EnglishSpeaking Proficiency. If you are interested in improving your English-speaking proficiency and used to listen to and/or watch English media, please take a moment to answer these questions.

Thank you

1-What are the audio and visual English media you frequently listen to and/or watch the most? (You can pick 3 at most.)

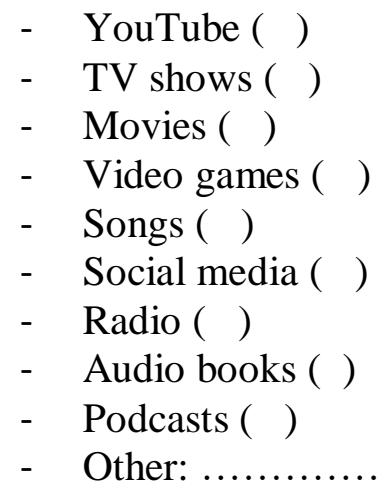

2- How long do you usually listen to and/or watch the above English media a day? (Check one box per row.)

\begin{tabular}{|l|l|l|l|l|l|}
\hline $\begin{array}{l}\text { Duration } \\
\text { Media }\end{array}$ & Never & $\begin{array}{c}\text { Less } \\
\text { than 1 } \\
\text { hour }\end{array}$ & $\begin{array}{c}1-2 \\
\text { hours }\end{array}$ & $\begin{array}{c}2-3 \\
\text { hours }\end{array}$ & 3-4 hours \\
\hline YouTube & & & & & \\
\hline $\begin{array}{l}\text { TV } \\
\text { shows }\end{array}$ & & & & & \\
\hline Movies & & & & & \\
\hline $\begin{array}{l}\text { Video } \\
\text { games }\end{array}$ & & & & & \\
\hline Songs & & & & & \\
\hline $\begin{array}{l}\text { Social } \\
\text { media }\end{array}$ & & & & & \\
\hline Radio & & & & & \\
\hline $\begin{array}{l}\text { Audio } \\
\text { books }\end{array}$ & & & & & \\
\hline Podcasts & & & & & \\
\hline
\end{tabular}

3-The above media can positively affect students' English-speaking proficiency.

- Agree ( )

- Strongly agree ( )

- Disagree ( )

- Strongly disagree ( )

4-In your opinion, which from the above media positively affects English-speaking proficiency the most? (You can pick 3 at most.)

- YouTube ( )

- TV shows ( )

- Movies ( )

- Video games ( )

- Songs ( )

- Social media ( )

- Radio ( )

- Audio books ( )

- Podcasts ( )

5-These media can improve students'..................the most. (You can pick 2 at most.)

- Vocabulary ( )

- Pronunciation( )

- Fluency ( )

- Grammar ( )

- Sentence structure ( )

- Other:

6-Rate the above items according to how much they are positively affected. ( 1 is the lowest effect and 5 is the highest effect.)

\begin{tabular}{|l|l|l|l|}
\hline ItemRate & 1 & 2 & 3 \\
\hline Vocabulary & & & \\
\hline Pronunciation & & & \\
\hline Fluency & & & \\
\hline Grammar & & & \\
\hline Sentence structure & & & \\
\hline
\end{tabular}

